protect themselves from threatening material by leaving and returning to the group as they wished.

We found that because of rapid turnover of patients, the longitudinal time frame of conventional out-patient groups could not be observed; thus the life of the group had to last a single session in many cases. In spite of this, orthodox therapeutic factors appeared to operate. It was impossible to regard the in-patient group as an independent entity. Our experience demonstrated how group work spills over onto the entire psychiatric ward and vice versa. Staff can feel very threatened by assuming the dual role of therapist and custodian. They need considerably more support and supervision than we provided. Finally, particular benefits accrued from the presence of psychotic members in the group who often penetrated effectively the defences of more integrated patients through their primary process thinking.

It was not our aim to determine the efficacy of our tailored group programme, but simply to see whether it could operate with a heterogenous population of patients. It is hoped that our experience will stimulate interest in using structured groups for the patient population described here and warn of the pitfalls.

\section{Acknowledgements}

My thanks to Mrs Gerrie Ballard and Miss Maureen Walton for typing this paper and to all the staff on West 3, Whitchurch Hospital.

\section{References}

Cox, M. (1976) Group psychotherapy in a secure setting. Proceedings of the Royal Society of Medicine, 69, 215-220.

(1983) The contribution of dynamic psychotherapy to forensic psychiatry and vice-versa. International Journal of Law and Psychiatry. 6, 89-99.

KANAS, N. (1980) The effectiveness of group psychotherapy during the first three weeks of hospitalization: A controlled study. Journal of Nervous and Mental Disease, $168,483-492$.

Novosel, S. (1986). A community group in the state hospital: A trainee's experience. Bulletin of Royal College of Psychiatrists, 10, 105-107.

YaLOM, I. D. (1983) In-patient Group Psychotherapy. New York: Basic Books.

This paper was presented as a poster presentation at the 1987 Annual Meeting of The Royal College of Psychiatrists.

\title{
Who uses a day hospital and for how long?
}

\section{A Liverpool study}

\section{Conway, Senior Registrar in Psychiatry, Liverpool Rotation; I. A. Davidson, Consultant Psychiatrist, Royal Liverpool Hospital; and M. E. DEwEY, Lecturer in Psychological Statistics, Department of Psychiatry, University of Liverpool, Liverpool}

The dichotomy caused by the National Health Service Act, Section 28 , which split the responsibility for the mentally disordered between the Minister of Health and local authorities has remained with us. Along with a separate GP service this dichotomy has caused inconsistencies, confusion and overlap in day care facilities. Although psychiatric day care has now become accepted as an essential element in the comprehensive psychiatric care of the mentally ill, its development has been unplanned and there is a great regional variation (Vaughan, 1983).

We report on the usage of a purpose built 40 place day hospital situated on the second floor of the main teaching hospital in Liverpool. The day hospital staff includes one sister, two staff nurses, two state enrolled nurses, one nursing auxiliary, one senior occupational therapist, one occupational therapy helper, one industrial helper, one part-time clerk and one full-time registrar from the Liverpool Rotational Training Scheme. Adjacent to the day hospital are two in-patient wards, an out-patient clinic and the University Department of Psychiatry. The catchment area served by the day hospital is that of an inner city area with a population of approximately 80,000 -identified by Jarman in 1983 as the most underprivileged wards in Liverpool.

Our study aimed to answer a number of questions:

(a) who is the referring agent and what is the goal on admission?

(b) what type of patient is admitted?

(c) how long do they stay and what factors influence the length of stay?

(d) why are they discharged? 


\section{The study}

There are two possible methods of studying psychiatric day patients. One method is to consider all new admissions over a given period of time and the second is to take a census of all the patients attending a day hospital at a particular point in time. We chose the former; by following all admissions through to their date of discharge, we eliminated the possibility of missing a chronic population.

A consecutive series of 295 admissions from 1 April 1980 to 31 March 1983 inclusive were examined. It is a retrospective study with information gathered from case-notes, records kept in the day hospital and from the standardised day hospital referral form.

\section{Who is the referring agent and what is the goal on admission?}

The referring agent was always a doctor working in the department of psychiatry. GPs did not have direct access to the day hospital and neither did the community nurses. Of the patients, $41.3 \%$ were referred from the in-patient unit and $36.6 \%$ from out-patients; $7.1 \%$ were referred following a domiciliary visit. Accident and emergency and liaison psychiatry accounted for $5.4 \%$ and $2 \%$ of referrals respectively. When referred $36.3 \%$ of patients were thought to need assessment in a day hospital setting; $34.9 \%$ were referred to maintain their present level of functioning or to prevent a deterioration; $10.2 \%$ were referred to the day hospital for behavioural therapy and $6.8 \%$ specifically needed social skills training.

\section{What type of patient is admitted?}

During the study period there were a total of 295 admissions representing 257 different patients of whom $182(61.7 \%)$ were women and $113(38.3 \%)$ were men. This distribution of sexes is similar to that found in the Birmingham study (Gath et al, 1973).

Of the patients admitted, $74.9 \%$ had a previous psychiatric history not including the index admission; $74 \%$ of the admissions were of people born in Liverpool and only 3\% of admissions were people born outside the British Isles; $55.8 \%$ had an educational level up to compulsory school leaving age only. Only $12.9 \%$ were in employment although another $24.7 \%$ were classed as housewives and $2 \%$ as students. Of patients admitted, $43 \%$ were single, $30.1 \%$ were married, $15.8 \%$ separated or divorced and $11.1 \%$ widowed. The employment level may reflect the general economic depression in Liverpool, especially in the inner city area, but it is also likely to reflect the fact that people in employment are less likely to be referred to day hospitals or are less likely to be willing to take time off work to attend.
How long do patients stay and what factors influence the length of stay?

Length of stay has been a focus of concern with regard to day hospital care. Of patients in the Birmingham study, $58 \%$ (Cross et al, 1972) were still attending 12 months later; $93 \%$ of patients attended Tegfan Day Hospital for more than one year, 37\% attended for more than two years (Pryce, 1982). In 1987 McGrath \& Tantam in Manchester found that $36 \%$ or 39 patients attended their day hospital for more than one year. In our study we analysed the length of stay in relation to six possible explanatory variables: age, sex, source of referral, area of residence, diagnosis and reason for discharge.

We chose to analyse on the log scale using iteratively weighted least square. This is equivalent to assuming that the variance is directly proportionate to the means. Analysis using main effects only and using main effects with a two way interaction failed to show any statistically significant effect of either source of referral or area of residence (Table I).

Only one two way interaction seemed to be significant, that between age and sex. They interact in such a way that for women increasing age is associated with a shorter length of stay, whereas for men the two are independent.

Reason for discharge is the most important source of variation in this dataset. The patients who improved stayed longest, 'drop-outs' had the shortest length of stay and those who did not improve had an intermediate length of stay.

The evidence of previous studies (Cross et al, 1972; Hassell et al, 1972; Pryce, 1982; McCreadie et al, 1984 ) is that the long-stay population in day hospitals tends to consist of male schizophrenic patients of middle age or over. In our study we did not find this to be so (Table II).

The Royal Liverpool catchment area overlaps to some degree with that of five day centres. Our data did not show that a high percentage of patients from the day hospital were referred on to day centres but it is possible that the presence of day centres influences the type of person referred to the day hospital in the first place but this would need further evaluation.

Examining the reasons why people were discharged from the day hospital, we found that $33.9 \%$ of patients dropped out, $41.4 \%$ were considered to have improved and so were discharged. Only $3.1 \%$ were noted to have worsened; $16.6 \%$ were transferred to the in-patient unit and the rest were transferred to other wards due to intercurrent physical illnesses.

\section{Comment}

The first day hospital in the United Kingdom opened in 1947 in London (Bierer, 1959). This day hospital 
TABLE I

Coefficients derived from iteratively weighted least-squares fit predicting length of stay in days

\begin{tabular}{|c|c|c|c|c|c|c|}
\hline \multirow{6}{*}{$\begin{array}{l}\text { Age } \\
\text { (per year) } \\
\text { Sex } \\
\text { Discharge } \\
\text { Reason } \\
\text { (Multiplier } \\
\quad \text { relative to } \\
\quad \text { unplanned) }\end{array}$} & \multirow{4}{*}{$\begin{array}{l}\text { Female } \\
\text { Male } \\
\text { Male } \\
\text { Improved }\end{array}$} & \multirow{2}{*}{$\begin{array}{c}\text { Multiplier } \\
0.985 \\
1.005\end{array}$} & \multicolumn{2}{|c|}{ 95\% C.I. } & \multirow{2}{*}{$\begin{array}{c}F \\
8.35\end{array}$} & \multirow{2}{*}{$\frac{d . f .}{1,254}$} \\
\hline & & & 0.977 & 0.993 & & \\
\hline & & 0.382 & 0.203 & 0.721 & 2.36 & 1,254 \\
\hline & & 3.237 & 2.430 & 4.322 & 29.89 & 3,254 \\
\hline & $\begin{array}{l}\text { Not } \\
\text { Improved }\end{array}$ & 1.561 & 1.037 & 2.349 & & \\
\hline & $\begin{array}{l}\text { Other } \\
\text { refers to ref }\end{array}$ & $\begin{array}{l}1.830 \\
\text { ther depar }\end{array}$ & $\begin{array}{c}0.916 \\
\text { nts, hos }\end{array}$ & $\begin{array}{l}3.656 \\
1 \text { etc., }\end{array}$ & & \\
\hline
\end{tabular}

Base value to which multipliers are applied 104.03 days

TABLE II

Coefficients derived from iteratively weighted least-squares fit predicting length of stay in days

\begin{tabular}{lllllll}
\hline Diagnosis: & Schizophrenia & 1.200 & 0.894 & 1.612 & 2.66 & 5,254 \\
(Multiplier & Neurosis & 1.126 & 0.819 & 1.550 & & \\
relative to & Personality disorder & 0.944 & 0.647 & 1.378 & & \\
affective) & Situational crisis & 0.555 & 0.327 & 0.943 & & \\
& Other & 0.819 & 0.555 & 1.210 & & \\
& & & & & & \\
\hline
\end{tabular}

was treating 1,200 patients per annum by 1957 and offered a range of treatments to both children and adults, including a ten bedded night unit. The reviews by Vaughan (1983) and Wilkinson (1984) show that development since 1959 has resulted in the expansion in the number of day hospitals but has not reduced their variety or their variability.

We examined the data over a three year study for inter year differences and the similarity between the years indicates that our sample is representative of the normal functioning of our unit. Admissions were accepted only following detailed discussion between the referring doctor and the day hospital staff, who as a team reserved the right to refuse admission. It was always the clear expectation that admissions to the day hospital lasting more than six months would be very exceptional indeed. We feel that this preselection would partly account for the length of stay of patients being in the lower end of McCreadie's range, who in 1984 suggested that $0-37.7$ per 100,000 of the general population aged $18-64$ needed long-stay day hospital places.

The programmes offered at the day hospital represent a fairly eclectic mix and are tailored to the needs of individual patients. They include a range of group activities including thrice weekly psycho- therapy groups. The ethos of the day hospital is to promote active treatment with regular review to ensure that patients needs are catered for and that patients are responding to continued attendance. The effect of different assessments and programmes would be an interesting area for further research if day hospital descriptions regularly elucidated these items.

Since these data were gathered the Royal Liverpool Day Hospital has been under considerable pressure with unfounded rumours of possible closure abounding. We feel that such a move would be detrimental to the unit as a whole and would greatly decrease the quality of care available to the population. After all, one of the main advantages of day hospital care is that it is cost-effective (approximately one third of the cost of in-patient care). It is clear from the data that closure of the day hospital would create a backlog of pressure on the wards and necessitate considerable change in the clinical management of patients.

\section{References}

BIERER, J. (1959) Theory and practice of psychiatric day hospitals. Lancet, 901-902. 
Cross, K. W., Hassall, L. \& Gath, D. (1972) Psychiatric day-care: the new chronic population? British Journal of Preventive and Social Medicine, 26, 199-204.

Gath, D. H., Hassall, C. \& Cross, K. W. (1973) Whither psychiatric day-care? A study of day patients in Birmingham. British Medical Journal, 1, 94-98.

Hassall, C., Gath, D. \& Cross, K. W. (1972) Psychiatry day-care in Birmingham. British Journal of Preventive and Social Medicine, 26, 112-120.

JARMAN, B. (1983) Identification of underprivileged areas. British Medical Journal, 286, 1705-1709.

- (1984) Underprivileged areas: validation and distribution of scores. British Medical Journal, 289, 1587-1592.
McCreadie, R. G., Robinson, A. D. \& Wilson, A. O. A. (1984) The Scottish survey of chronic day patients. British Journal of Psychiatry, 145, 626-630.

MCGrath, G. \& TANTAM, D. (1987) Long stay patients in a psychiatric day hospital. A casenote review. British Journal of Psychiatry, 150, 836-840.

PryCE, I. G. (1982) An expanding 'stage army' of long stay psychiatric day patients. British Journal of Psychiatry. 141, 595-601.

Vaughan, P. J. (1983) The disordered development of day care in psychiatry. Health Trends, 15, 91-94.

WILKINSON, G. (1984) Day care for patients with psychiatric disorders. British Medical Journal, 288, 1710-1712.

\title{
A staff group in a burns unit
}

\section{Managing patients' psychological needs}

\author{
D. ANTEBI, Research Registrar, Burden Neurological Hospital, Stapleton, Bristol; and \\ N. R. Ambler, Clinical Psychologist, Glenside Hospital, Stapleton, Bristol
}

The issue of the relationship between physical illness and psychological disorder has a long and chequered history. It is therefore difficult to derive practice implications. However, there are associations between methods of patient care and long-term psychological and physical functioning which have provided some guiding principles (Nichols, 1984). This paper describes how these principles have been applied in a regional burns unit.

Psychological care is often neglected in general hospitals. After illness or trauma, when distress would be expected, it is often either ignored or regarded as disruptive. This distress tends to be left to be managed by those with the most patient contact, i.e. nurses, and yet, they often feel ill-prepared and untrained for this. Furthermore, the ward environment offers little privacy and the predominant emphasis on physical care engenders the feeling of conveyor belt medicine.

The psychological needs of patients in hospitals are wide-ranging and are influenced by a number of factors. These include the ability to cope with stress, event factors such as degree of trauma and environmental factors such as family support. Burns patients are no exception. Added to this, they have to cope with painful treatment procedures, protracted hospital stay and disfigurement. As a group, they are also more likely to have pre-existing problems such as epilepsy, dementia, mental handicap and alcoholism. It is not surprising, therefore, that a one year followup study of severely burned patients revealed that two thirds were suffering persistent psychological problems (White, 1982). The way in which hospital staff manage psychological distress during the early stages of recovery is likely to have implications for patients' longer term adjustment. Awareness of this led the staff of the local adult regional burns unit to get in touch with us to discuss ways in which this aspect of their work could be developed.

We had several meetings with the burns team about how this might be achieved. There already existed a system of referral to the psychiatric service for severe psychological disturbance. However, their request did not concern the small proportion of extreme cases but the issue of general psychological care. We agreed this would be better dealt with by means of a staff group. After discussion, we decided this would run once a week for an hour in a side-room of the 20-bedded burns unit. Rather than set a timetable of topics for discussion, any member of staff could raise any issue or aspect of patient care in the meeting. It was open to any member of the multidisciplinary team to attend but there was no compulsion to do so. We were concerned that these meetings should not serve as an alternative psychiatric service and we therefore made it explicit at the outset that we would not see patients. The structure of the group was necessarily open due to the limitations imposed by the nursing shift system. The declared aim of the group was to raise confidence and awareness in dealing with psychological issues in the unit. During the first three months attendance was variable but this improved to consistently between seven and eleven. 